\title{
SOCIOMETRIC PARTICULARITIES IN THE SOCIAL INTEGRATION OF ADOLESCENTS BY PRACTISING ACTIVE FORMS OF TOURISM
}

\author{
Maria GROSU \\ State University of Physical Education and Sport, Chisinau, Republic of Moldova \\ e-mail: catedra-natatie@mail.ru
}

\begin{abstract}
Currently, teenagers face the difficulty of integration and socialization in the new membership group. Knowing the adolescent team not only involves knowing the personality of its members but much more, and this can be achieved by practising various active forms of tourism that are considered to be means of influencing and forming the human character of fairness, modesty, courage and last but not least, teamwork.
\end{abstract}

Key words: sociometric peculiarities, adolescents, active forms of tourism, gender groups.

\section{Introduction}

In the conception of Popescu-NeveanuP.(1978), integration is a biological, neurological and psychological process of embracing, assimilating the implication of an element (impulse, signal, operation, information) by another over-coordinated unifying element.

Social integration is achieved through the unselfish participation and participation of the individual in a set of norms, values and attitudes common to the group. Social integration involves accommodating, solving conflicts between aspirations and behavioral attitudes, between individuals, groups. It can be accomplished by domination, compromise, conciliation, conversion [1, 4].

At present, social group members represent one of the main issues of society with multiple theoretical and practical implications in the measurement of emotional relationships.

The qualitative differentiation of groups derives from the number of members they make and the types of interactions that develop between them.

The finality of adolescent integration is the optimal adaptation of the system to the new group. Increasingly effective integration implies an important stage in the development and formation of human personalities. The adolescent's essence as a social group is relevant in the process of achieving the strategy of integrating and reproducing the social structure [3].

Research hypothesis: It is assumed that by implementing a program that contains various active forms of tourism, adolescent groups will become more homogeneous, and the number of rejections within the group will decrease significantly.

The purpose of the research is the sociometric analysis of the group of adolescents as a result of practicing forms of active tourism.

Objectivesoftheresearch:

1. Analysis of the specialized literature on the specificity of the sociometric particularities in the social integration of adolescents by practicing forms of active tourism.

2. Determination of the level of socialization integration, realism in the adolescent group.

The subjects of the research were 30 adolescents from the municipal sports boarding high school in Chisinau.

\section{Materials and methods}

The following research methods were used to achieve the objectives: analysis of the scientificmethodical literature; pedagogical observation and sociometric method.

The research of specialists' concepts regarding practising various forms of active tourism in order to socialize adolescents was based on the sociometric test applied to adolescents, which aimed to determine the level of adolescence integration and relationships within the collective group.

The socio-demographic test was carried out on a sample of 30 adolescents from the municipal boarding sports high school of Chisinau.

\section{Results and Discussion}

The advantage of applying the sociometric test to the adolescent group gave us a radiograph of the positive and negative relationships of each member of the group, which involved: knowing how the team evolved and the stage reached in forming the group's cohesion.

Thus, as a result of analyzing the results of the sociometric test in the group of 30 adolescents, the preference was 9 persons and the rejected 21. This investigative tool constituted a special support in knowing the socio-functional fundamentals of a group, offering the possibility of action and interventions on the group, which takes into account its internal organization, to improve its functioning, group cohesion, and to reestablish homogeneous teams by applying a program of forms of active tourism. 
The study of demonstrative social direction of inter-personal relationships and the components of certain groups in our research, the group submitted to pedagogical experiment was performed using sociometric test which was based on the questionnaire technique with sociometric test wheretwo questions were addressed to capture affective relationships of preference or rejection.

The sociometric test is considered the main instrument and starting point in knowing the different aspects of the interaction process that is manifested in the adolescent group. It offered us only the raw material about the relational aspects of the teenager and the group of each member.

In order to perform these tests, the sociometric method was used in which the stage of group and individual relations was followed.

The questionnaire was applied to groups of adolescents in the 8th grade of the boarding sports high school of Chisinau.

The questionnaire contained two questions:

1. Name three of your colleagues, with whom you would like to go in a tourist activity (excursion, tourist marches, actions and tourist meetings)?

2. Name three of your colleagues, who would not you want to go in a tourist activity (excursion, tourist marches, actions and tourist meetings)?

Regarding the psychological knowledge of the adolescent group in general, the sociometric test provided valuable information both by confronting the selective and perceptual data obtained in the investigation and by aggregating the motivation of the choices / rejections that denotes the way the adolescent is projected outside by its membership group.

Knowing the adolescent team does not just knowabout the personality of its members, but much more. Knowing the teenage group is about capturing those characteristics that define it as a whole, as a standalone unit, as a social group.

Two answers to each question were given. The choices were marked with (+) and the rejections with (-). The options were recorded in a double-entry table where members of the class were scored vertically and horizontally, and their relationship with (+), for attractions and (-) for rejection. The information provided by the sociometric test is very important for the measurement of emotional relationships within the members of the social groups. Based on these, we were able to notice the positive orientation of the relations between the members of a group.

The basic element of the sociometric test is positive (attraction) choice, negative (rejection) or indifference expressed in response to the researcher's questions, in our case they are processed based on the centralizing table or the so-called sociometric matrix (Table 1).
We can say that the identification of personal traits gives us the opportunity to better understand the meaning of the roles played by the pupils, and through them to enter into the mechanism of the interaction process, a mechanism that triggers and determines the characteristics of the collective as a whole. Knowledge can also reverse the way, from the defining features of the collective, through the behaviors that result from the exercise of the roles, to the internal conditions and the psychological peculiarities of its members. In this second sense we can say that the sociometric techniques provide a thorough knowledge especially of the informal / affective structure but also indirectly of the personality characteristics of adolescents. Each collective has, as we have seen, its own structure, which manifests itself differently. Many methods and techniques can be used to investigate and research small social groups. One of these is the sociometric test that aims to measure affective-sympathetic relations between members of social groups.

The analysis of the group to which we refer, the one subjected to the pedagogical experiment, was done in order to know the level of socialization and relationship within the group and some sociometric aspects such as the existing relationships, or those that develop among the members of the group, thus realizing the communication and socialization. A way to interact and socialize with groups, through various forms of active tourism and namely the program proposed by us.

The sociometric matrix was one of the methods used to show the level of communication and the type of relationships found in the group of pupils, the relationship between the individual, the group and the society as well as the explanation given to the social action, which is the only relationship of the teenager (integrated into the group, community, society) with the natural and social environment in which material and spiritual values are produced or reproduced, thus ensuring social progress.So, following the sociometric test, we noticed that some people obtained quite large indices and some rather small.

Following the sociometric matrix, we noticed that the number of rejections is higher compared to the number of choices. 
Table 1. Sociometric matrix

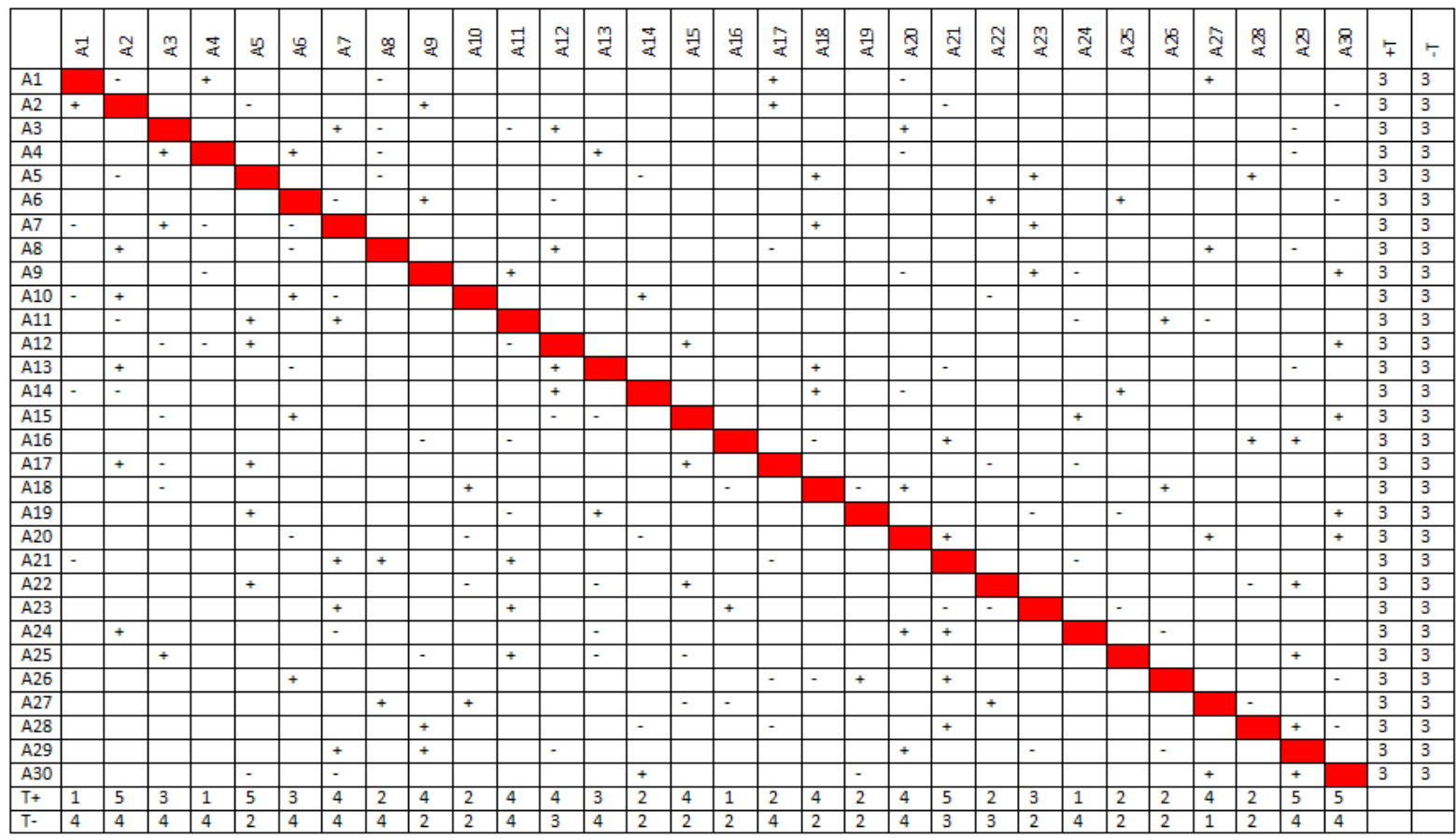

In the literature, sociometry is presented either as a method of research, which allows the measurement, ordering and graphical presentation of social and psychosocial phenomena and at the same times a method of research Mihu, A. [5, p. 35]. The diversity of views on the status of sociometry is determined by the plurality of criteria used by one author or another.

The elaboration of one or other of the sociological research methods was determined by the need to capture the multitude of components of social life in the process of knowledge in order to understand the complex mechanism by which the facts of real life are produced.

Through the sociometric study we have appreciated the concrete position of each adolescent within the group as well as the core of relationships around a teenager who is in constant contact with other teenagers.

The sociometric matrix allowed us to place the data in a double entry table in which the alphabetical numbering of the subjects was passed on the first line and the column, and the response sheets were passed one by one in the array.

Horizontally, the choices and rejections registered, and vertically, in columns, the choices and rejections received. The last position of the lines and columns included the sum of the choices and rejections issued (horizontally) or received (vertically).

The test was performed using the sociometric matrix (Table 2), based on which the sociometric indices of the group (popularity, accepted, marginalized and indifferent) were established.

On the basis of the sociometric matrix, the sociogram on the indices (popular accepted), which is a graphic illustration of the interrelations within the group (Figure 1), and the sociogramon indices (indifferent and marginalized) (Figure 2) was made.
In order to appreciate the initial socialization level of the experimental group, the sociometric method was applied where the stage of group and individual relationships was followed by determining the group and individual indices.

Concerning the psychological knowledge of adolescents, the sociometric test was carried out which provided valuable information both by confronting the selective and perceptive data obtained in the survey (Table 1) and by summarizing the motivation of the choices / rejections where it was presented how each member is shown by its membership group.

The 30 tested subjects (numbered from A1 to A30) are placed in the concentric circle according to their degree of popularity in the class group.

The informal leaders of the group (with the highest score) are placed in the center of the circle (a circle numbered from the inside outwards). The more a pupil has a lower score, the more he moves away from the center of the circle or even from the group, being not preferred and not preferring anyone (indifferent).

The sociogram of the group is that of concentric circles, "target" type, proposed by Northway, M., [2], where the central position is occupied by those with strong social status (popular), to the edge being the accepted ones.

Applying the sociometric test allowed all members of the group to talk about the positive or negative relationships they have with others, each of them should verbalize attitudes of choice or rejection in relation to group partners.

From Figure 1 we can highlight the accepted popular indices obtained in the test and from (indifferent and marginalized indices) (Figure 2).

Through this sociometry a comparative analysis was performed between the positive and negative 
variables within the group indices centralizer (popular, accepted, indifferent and marginalized).

As a result of the choices and rejections performed by the group of subjects (Table 1), the sociometric indices or the group and individual statistical indicators were calculated in the sociometric matrix and the appropriate chart was drawn up in the form of sociogram giving a complete reference to the structure of the group as well as of each subject in its relations with the other subjects.

Table 2. Group Indices for Positive and Negative choices

\begin{tabular}{|c|c|c|c|}
\hline No. of preferences & $\begin{array}{c}\text { No. of subjects with the } \\
\text { samepreferences }\end{array}$ & $\begin{array}{c}\text { Preferential psychosocial } \\
\text { value }\end{array}$ \\
\hline 7 & 1 & 0.24 & Popular \\
6 & 2 & 0.20 & \\
\hline 5 & 2 & 0.17 & Accepted \\
\hline 4 & 5 & 0.10 & \\
2 & 8 & 0.06 & \\
1 & 3 & 0.03 & Indifferent \\
\hline 0 & 2 & & Marginalized \\
\hline-1 & 8 & 0 & \\
-3 & 2 & -0.03 & \\
-4 & 4 & -0.06 & \\
-6 & 2 & -0.10 & \\
\hline-7 & 2 & -0.13 & \\
\hline
\end{tabular}

As we can observe the sociometric indices in Table 2, there is a variation in the fact that, in the group of questioned adolescents, prevail people who have had enough sociometric indices (0.24), specifying that they are the leaders of the membership group who registered a lower sociometric index $(-0.10)$, being persons who are not part of the membership group.
Applying the sociometric test allowed all members of the group to talk about the positive or negative relationships they have with others, each of them should verbalize attitudes of choice or rejection in relation to group partners.

Figure 1. The sociogram of the adolescent group (popular and accepted indices)

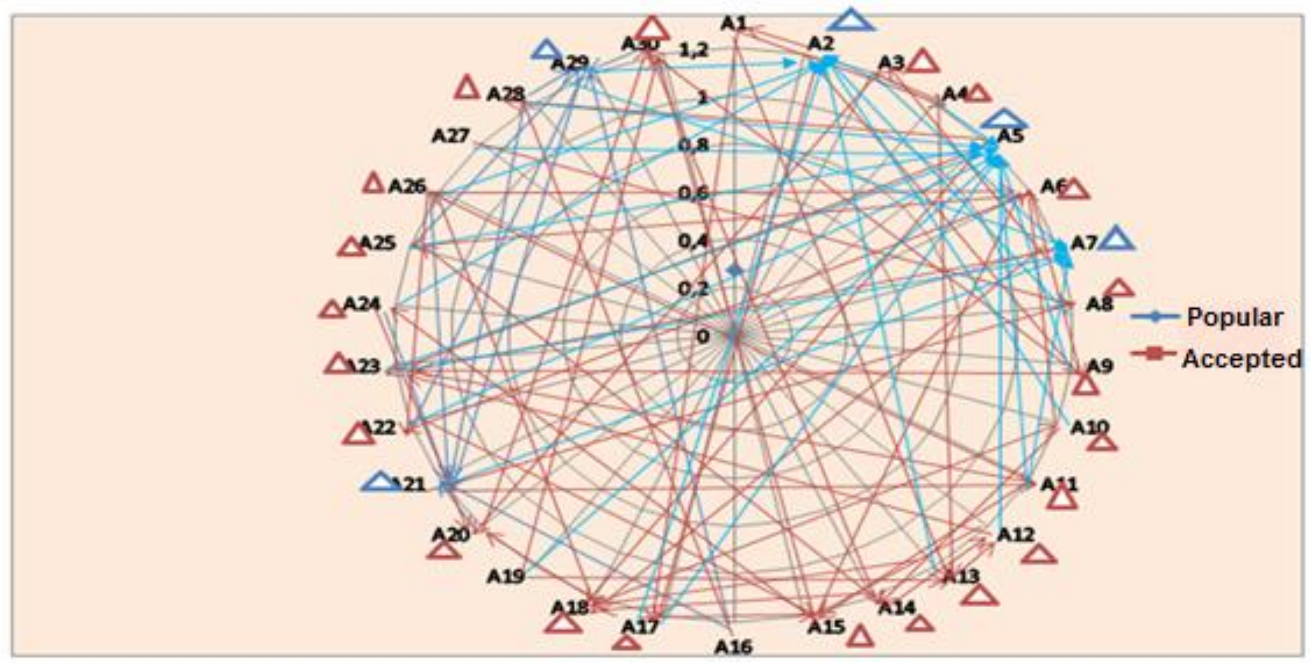

Thus, with $\mathrm{T}+$ were registered the subjects who enjoyed the most popularity marked with blue(A2, A5, A7, A21, A29).
But with $\mathrm{T}$ - were registered the subjects with a lower popularity index accepted marked with Bordeaux 
(A3, A4, A6, A8, A9, A10, A11, A12, A13, A14, A15, A17, A18, A20, A22), A23, A24, A25, A26, A28, A30).

Analyzing the data obtained at the initial stage of the experimental group, we can argue that applying the sociometric test to the group of adolescents allowed us to establish the level of socialization the climate within the group, the internal hierarchy of the group, highlighting the central position in the group.

The sociogram highlighted the group's overall structure, its homogeneity and cohesiveness in the subgroups, the existence of a core nucleus and its bonds with other subgroups, the presence of the leaders.

Mini-leaders from mini-groups formed the group of subjects undergoing the scientific research.

Figure 2. Sociograma of the adolescent group of (indifferent and marginalized indices)

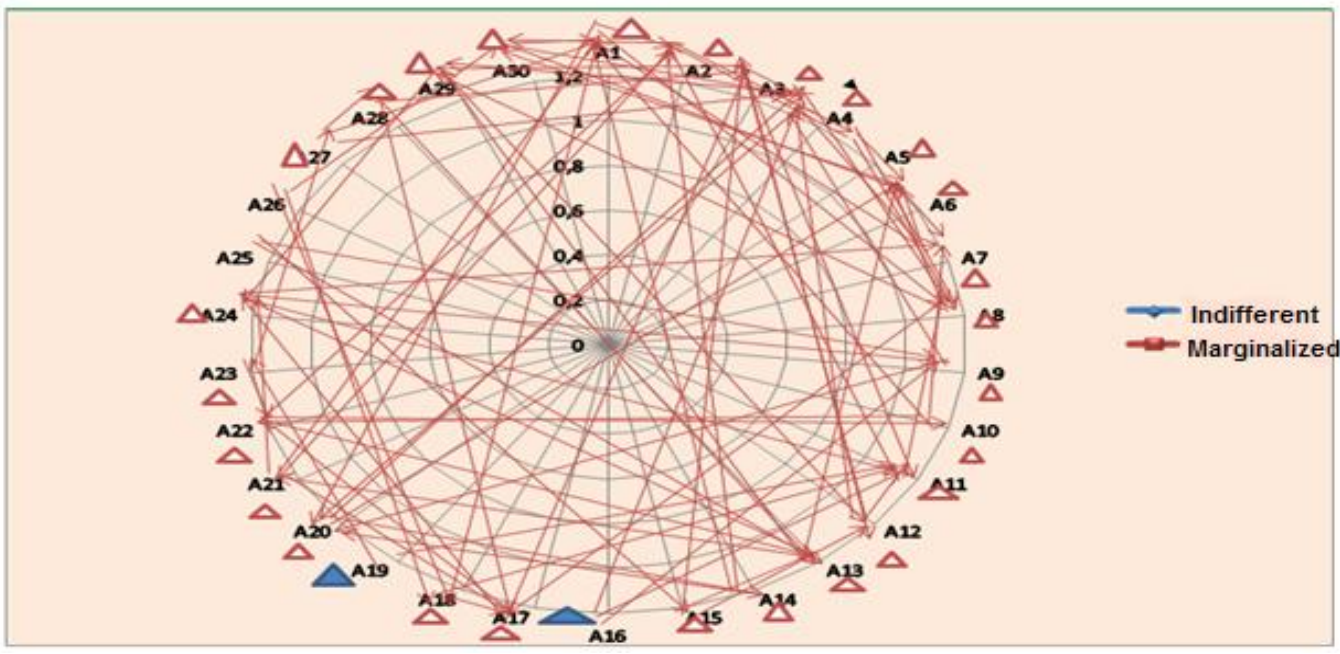

By analyzing the sociometric indices of the group it was shown that the surveyed subjects showed a low level of sociometric indices in accordance with the choices made, which shows that relations at the level of the subjects in the group are not equivalent. It is a state of low socialization level, due in particular to the level of relationship of members within the group.

In the analysis of the sociometric indices there is a dissociation of two subjects from the rest of the group, which have low indices with (indifferent) index obtained on the basis of the received attractions.

By analyzing the sociometric group indices in the initial testing it can be observed that the subjects demonstrate a low level of indices in accordance with the choices made, which shows that the relations at the level of the subjects in the group are not homogeneous. There is a low level of socialization due to the low level of relationship among members of the group.

\section{Conclusions}

We can mention that thecollective sociogram gave us the possibility to know the preferential structure and affective relations that are established within the collective, graphically indicating who's interacting with in terms of affinity.

The advantage of applying the sociometric test gave us a radiograph of the state of positive and negative relationships at a given time and in a given situation, which may be radically different for another situation; knowing how the team evolves; Knowledge of the stage reached in the formation of the group cohesion. Thus, as a result of the sociometric test in the group of 30 adolescents, the preferred were A5, A13, A2, and A24, A11, A2 were rejected. This investigative tool was a special support in knowing the socio-affective bases of a group, actions, an intervention on the group, taking into account its internal organization, improving its functioning, group cohesion, and re-establishing homogeneous teams by implementing a program of forms of active tourism.

\section{References}

1. Grosu, M., Onoi, M., Mindrigan, V. (2018). Theoretical aspects regarding the socialization of adolescents in the geneder groups through tourism activities. In: The materials of the international scientific congress „Sport. Olympism. Health", 3rd edition. Chisinau: Ed. USEFS, 2018, pp. 48-50.

2.http://www.rasfoiesc.com/educatie/didactica/ABORDAR EA-SOCIOMETRICA-A-GRUPU35.php. (accessed October $15,2018)$. ML Northway

3.Iluţ, P. (2006). Clarifications on gender issues. Review of Sociology of Romanians (Romanian Sociology), Vol. IV, no. 3, pp. 68-85.

4.Lupasco, O., Nicoleiciuc, N. (2019). Integration and Socialization of the Young Specialist in the New Group of Parallelism. In: materials of the student's scientific conference „Current Problems of the Physical Culture Theory and Practice". Chisinau: USEFS, 2019, p. 8-12.

5. Mihu, A., Constantinescu, M., Berlogea, O. (1970). Laboratory of Sociology. In Methods and Techniques of Sociology. Bucharest: Didactic and Pedagogic Publishing House, p. 35

6. Popescu-Neveanu, P. (1978). The Human Psychic System. „Psychology” 3/, p. 22 